\title{
Unravelling Legacy: A Triadic Actor-Network Theory Approach to Understanding the Outcomes of Mega Events
}

\author{
Jordan Dawson* \\ PhD researcher \\ School of Sport and Exercise Health Sciences (SSEHS) \\ Loughborough University \\ Loughborough LE11 3TU \\ United Kingdom \\ Phone +44 (0) 1509226302 \\ J.O.Dawson@lboro.ac.uk
}

Dr Heike Jöns

Reader in Human Geography

Department of Geography

Loughborough University

Loughborough LE11 3TU

United Kingdom

Phone +44 (0) 1509228199

H.Jons@lboro.ac.uk

*Corresponding author 


\section{Notes on contributors}

Jordan Dawson is a doctoral candidate in the School of Sport and Exercise Health Sciences at Loughborough University. His research project examines the profiles, practices and perceptions of visitors to the Queen Elizabeth Olympic Park in East London. Jordan’s main areas of research are urban regeneration, the legacy of mega events, sporting and spatial inequality and post-industrial leisure practices. Jordan has been involved in the development of Loughborough University’s peer-led PhD support network and served as this university’s PGR Programme President in the academic year 2015/2016.

Heike Jöns is a Reader in Human Geography at Loughborough University. She has widely published on the geographies of scientific knowledge production, including the edited collection Geographies of Science (with P. Meusburger \& D.N. Livingstone, 2010, Dordrecht) and Mobilities of Knowledge (with P. Meusburger \& M. Heffernan, 2017, Dordrecht). Over the past 17 years, Heike has developed a constructive critique of social constructivism and actor-network theory in different empirical contexts that is most prominently portrayed in her book Grenzüberschreitende Mobilität and Kooperation in the Wissenschaften (Boundary-crossing mobility and cooperation, 2003, Heidelberg). 


\title{
Unravelling Legacy: A Triadic Actor-Network Theory Approach to Understanding the Outcomes of Mega Events
}

\begin{abstract}
Mega events have recently attracted the attention of social scientists due to their important role for festival capitalism, urban regeneration and political propaganda. Their planning stage often produces elaborate strategies for maximising the benefits before, during and after the actual event, which has given rise to interdisciplinary studies of event legacy and leveraging. This paper aims to advance ongoing debates on the outcomes of sports mega events by bringing together the literatures on mega event legacy, leveraging and actor-network theory. Drawing on a case study on the usage of the Queen Elizabeth Olympic Park, the main legacy of the London 2012 Olympic Games, the paper develops a novel conceptual framework for researching the multi-scalar outcomes of mega events and locating respective studies within the resulting wider research agenda. The proposed concept extends Preuss' (2007) legacy cube in two ways by visualising its five research dimensions in the legacy rings and using three rather than two sub-dimensions per ring, thereby replacing the restrictive dyads of dualistic thinking through more comprehensive but still manageable triads of triadic thought (Jöns, 2006).
\end{abstract}

\section{Keywords}

legacy; mega events; practices; actor-network theory; London 2012;

Queen Elizabeth Olympic Park 


\section{Introduction}

Mega events have attracted growing attention by a range of academics, especially within the social sciences (e.g., Roche, 2000; Weed et al., 2012; Giulianotti et al., 2015). Sport-based mega events have been a main focus due to the importance placed upon them by a diverse range of interest groups, including local and national governments, sporting bodies and organizing committees (Grix, 2014). Mega events such as the quadrennial Olympics (both Summer and Winter Games), FIFA Football World Cup, Commonwealth, Asian and African Games and regular major events such as the American Football Superbowl and the Africa Cup of Nations have become desirable to host cities and nations for a variety of reasons (Müller, 2015a). Those bidding for mega events emphasise often not only the sporting event but also its longer-term outcomes by focussing on legacy (Holt \& Ruta, 2015) and leveraging (Grix, 2014), thus aiming to create positive and avoid negative event outcomes.

Legacy has become a buzzword for the often elusive strategies employed by policy makers in the context of a temporary sporting festival (Steinbrink, Haferburg \& Ley, 2011). As a concept, it has become synonymous with large-scale transformations of both a tangible and intangible nature (Preuss, 2007). Yet the term is often used interchangeably with a variety of notions such as heritage, impact and effect. Moreover, it has become a catch-call concept for the wider public that is stretched beyond sports to stress the economic appeal of a variety of mega events in times of neoliberal festivalisation (Tomlinson, 2014). Event leveraging implies a slightly different perspective because it refers to academic debates interested in shifting the focus from post-hoc evaluations of an event's economic, social and environmental impacts to the identification of effective 'strategies and tactics that can be implemented prior to and during an event in order to generate particular outcomes’ (Chalip, 2006, p. 112).

This paper aims to contribute to both types of interdisciplinary debates about mega events by conceptualising their outcomes along a temporal spectrum of short-term effects, 
medium-term impacts and long-term legacies using a practice-based approach. Specifically, we draw on mega event legacy theory (MELT) — as advanced in sports economics (Preuss, 2007) —and actor-network theory (ANT) —as developed in sociological studies of science and technology (Kuhn, 1962; Biagioli, 1999; Latour, 2005)—to propose a multidimensional framework for unravelling the nature and outcomes of mega events. We argue that the proposed multidimensional notion of the 'legacy rings' helps to advance conceptual understanding, empirical operationalisation and strategic planning because it is inclusive of a range of research perspectives in the largely separate bodies of literature on event legacy and leveraging (for a notable exception, see Grix, 2014). The proposed legacy rings also respond to wider debates about the limiting nature of using two categories in social theory, such as agency and structure (Giddens, 1984) or nature and society (Latour, 1993), by replacing such restrictive dyads of dualistic thinking through more comprehensive but still manageable sets of three categories, thereby promoting conceptual triads of triadic thought (Jöns, 2001, 2006).

In order to develop this conceptual argument about the outcomes of mega events, this paper proceeds in three parts. First, we review recent research on mega event legacy, event leveraging and actor-network theory (ANT), thereby publicising the latter in leisure studies and sports science, where these ideas have not yet been widely discussed (for an exception, see Kerr, 2014; Thompson and Nesci, 2016). Second, in the spirit of the 'ANT and after' movement (Law \& Hassard, 1999) that seeks to develop this practice-based approach to knowledge production in a collective way (Latour, 1999a), we specifically draw on Preuss' (2007) 'legacy cube’ and Jöns’ (2006) 'trinity of actants’ to develop the framework of 'legacy rings' that moves social theorising towards more complex triadic thought. Finally, we demonstrate this concept's usefulness by discussing an empirical case study on park visitors' profiles and practices in the Queen Elizabeth Olympic Park, the largest material legacy of the London 2012 Olympic Games. 


\section{Joining legacy, leveraging and actor-networks}

Mega events can be characterised as 'large scale cultural (including commercial and sporting) events [that] have a dramatic character, mass popular appeal and international significance’ (Roche, 2000, p. 1). Together with festivals, mega events are part of wider urban spectacles, or impressive public displays 'that involve capitalist markets, sets of social relations, and flows of commodities, capital, technology, cultural forms and people across borders’ (Gotham, 2005, p. 227). Allen et al. (2011) situate mega events within a hierarchy ranging from community-based events via major and hallmark events to mega events, which means that our paper, being aware of key differences between events of different geographical reach (Black, 2014), focuses on those latter types involving bidding processes and structural environmental change.

Since the 1970s, mega events have increasingly been instrumentalised by political decision-makers for socioeconomic and urban development. Host cities have used mega events and associated infrastructure to regenerate post-industrial urban landscapes (Poynter \& MacRury, 2009; Smith, 2012) and place themselves within the global shop window to attract tourism and investment (Mascarenhas, 2014; Gruneau \& Horne, 2016). Paradoxically, mega events have reinforced competition between cities, nation states and global geopolitical alliances, during the Cold War on both sides of the Iron Curtain - from Moscow 1980 to Los Angeles 1984 - and subsequently in different regimes of free market and state capitalism such as London 2012 and Sochi 2014 (Müller, 2014).

Less certainty exists in the academic literature about the aftermath of the actual festival aspect of mega events and especially the nature of their long-term impact (Brimicombe, 2015). In regard to sports mega events as the main focus of this paper, one set of related debates refers to the notion of 'legacy', succinctly defined by Preuss as follows: 
irrespective of the time of production and space[,] legacy is all planned and unplanned, positive and negative, tangible and intangible structures created for and by a sport event that remain longer than the event itself (2007, p. 211).

Yet the value of the notion 'legacy' is contested because an International Olympic Committee (IOC) symposium on the legacy of the Olympic Games — hosted in Lausanne in 2002 — found that this term was not easily transferable into different language contexts. In French, one of the IOC’s official languages, the term héritage is preferred - a word embodying the past more than the future (IOC, 2002). Apart from this multilingual elusiveness and ambiguity, Cashman (2005, p. 15) argues that the term legacy is even 'dangerous' in nature because it concentrates on positive impacts of mega events. As shown in a statement issued by the Department of Culture, Media and Sport (DCMS) on the London 2012 Olympic Games, namely that 'legacy means ensuring a positive impact' (DCMS, 2014, p. 14), organising committees, governments and sporting organisations are reluctant to acknowledge negative impacts of mega events. A third criticism refers to the broadening nature of legacy because Tomlinson (2014) notes that when elastic is stretched too far, it snaps, thereby losing its precision, conceptual clarity and value.

These debates about appropriate terminologies are reflected in wider concerns about legacy plans often falling short of the original goals due to the temporary nature of organising committees, limited conceptual understanding and methodological challenges in regard to measuring legacies (Phillips \& Barnes, 2015). Hence the research on event leveraging has tried to develop strategies that enhance wider economic, socio-cultural and environmental outcomes at all stages and scales of events, including those at the community level (Chalip, 2006, 2014; O’Brien \& Chalip, 2008; Smith, 2013; VanWynsberghe, 2014). Chalip (2006), 
for example, suggests to foster social interaction and prompt a feeling of celebration among community stakeholders by enabling sociability before and after the event, creating eventrelated activities, facilitating informal social opportunities and producing widely themed parallel events. While some of this worked well during the Los Angeles (Wilson, 2015) and Sydney Olympics (Chalip, 2006), such leveraging strategies within the local community seemed to have been largely absent during London 2012, even if the London Legacy Development Corporation (LLDC) now tries to enrol the local community through postGames leveraging strategies such as contextualised temporary art instalments on local history and heritage (LLDC, 2013).

While some of the leveraging strategies have worked, major challenges have been discussed in regard to branding because local companies are not eligible sponsoring partners of mega event organisation structures and thus not allowed to use related logos (Smith \& Fox, 2007). Smith (2013) suggests that there is also a danger of covering-up negative social outcomes such as the displacement of local communities in the wake of mega events by emphasising the participation of a selected few either before, during or after the event. Comparing the literatures on event legacy and leveraging therefore gives the impression that the legacy strand has mainly been interested in major and larger mega events, whereas leveraging strategies, especially social ones, have more often considered smaller community events that are less hampered by commercial interests. While both lines of inquiry view each other critically (Chalip, 2014; Preuss, 2014), we strive to develop the strengths of their research perspectives respectively.

We specifically aim to advance conceptual thinking across mega event legacy and event leveraging research in two ways by bringing into conversation MELT, our acronym for mega event legacy theory, and conceptual debates in both science and technology studies and geography about actor-network theory (ANT). First, we suggest a small but significant shift in 
terminology from legacy as a wider concept to the more differentiated triad of 'effect/impact/legacy’ and thus to three terms that are addressed as outcomes in leveraging research (VanWynsberghe, 2014). Second, we propose to synthesise existing case studies and novel research perspectives in the notion of the 'legacy rings', a multidimensional framework for researching the outcomes of (sports) mega events.

\section{MELT and the 'legacy cube'}

A more in-depth conceptual understanding of the contested notion of legacy has been encouraged by both the inclusion of this notion into the IOC Charter in 1999 and by the IOC symposium on the legacy of the Olympic Games in 2002 (IOC, 2002). Initially prominent in tourism studies (Ritchie, 1984), concepts for measuring legacy have multiplied over the past two decades and shifted from an emphasis on economic aspects to broader understandings of legacy (Brimicombe, 2015). For example, Hiller (1998) proposed a three-strand model that analyses the concept of legacy along the dimensions of forward, backward and parallel linkages. Forward linkages are directly causing impacts of mega events such as employment. Backward linkages evoke pre-legacy contexts and especially the circumstances in which the event bid was compiled and submitted, thereby anticipating the current emphasis on constructing a narrative behind planning for legacy prior to the event (MacRury, 2015). Parallel linkages acknowledge the unintentional impacts of hosting mega events, including negative aspects that are often silenced by the organising bodies, such as the displacement of local populations and other agents (Black \& Bezanson, 2004).

Several conceptual frameworks have explored event legacy with a focus on empirical studies of its impact on economic and urban regeneration (e.g., Kassens-Noor, 2012; Preuss, 2014). Two prime examples are the 'legacy cube’ proposed by Preuss (2007) and the 'legacy radar’ discussed by Dickson, Benson, and Blackman (2011). Preuss’ (2007) legacy cube 
visualises three dimensions of legacy that should be considered when planning and analysing mega event legacy: planned/unplanned, positive/negative and tangible/intangible (Figure 1). According to Preuss (2007), it is also important to consider that all three dimensions vary across time and space. This multi-scalar concept of legacy has been widely discussed in the academic literature, adding the unplanned, negative and intangible dimensions of legacy to MELT (e.g., Smith, 2013; Misener et al., 2013; Preuss, 2014).

\section{[Please insert Figure 1 about here]}

At the same time, there has been a desire to develop the legacy cube further by adding new dimensions and scales. For example, Dickson, Benson, and Blackman’s (2011) legacy radar builds upon existing typologies of tangible and intangible legacy and the other aspects of Preuss' (2007) legacy cube in order to add in costs, whether these are financial, opportunity or time costs. Their six point Likert scale radar thus outlines planning, 'hard' and 'soft' structures that can be positive and negative, tangibility, timeframe, spatial impact and costs. Leopkey and Parent's (2012) work challenges this emphasis on economic costs by outlining the importance of social, cultural, political, environmental, psychological and symbolic event legacies in existing case studies. We therefore suggest that economic costs represent only one type of legacies that could be investigated according to Preuss' (2007) five dimensions of the legacy cube in similar ways as the other types of legacies identified by Leopkey and Parent (2012). This means that the costs of the legacy radar address a specific research theme rather than an additional research dimension. Accordingly, we continue to work with the five research dimensions of the legacy cube rather than adding a sixth dimension on costs.

From a human geographical perspective, three main aspects that could be considered more prominently within MELT, both conceptually and empirically, are the everyday 
practices, experiences and perceptions of a range of visitors to former mega event sites such as the Queen Elizabeth Olympic Park in London. According to Hylton and Morpeth (2012), these wider public opinions and experiences, especially in regard to local populations, are often neglected by policy makers post-Olympics. In order to advance theorising in MELT, we therefore suggest considering the practices of diverse human actors, whether athletes, local populations or tourists, more prominently in mega event studies. The following section will show that this inclusion of the general publics' views and practices requires a radical move from dualistic to triadic thinking by using three rather than two sub-dimensions in the proposed framework of the legacy rings. In essence, we will take Preuss’ (2007) five research dimensions as the basis for conceptualising five legacy rings, but we will differentiate three rather than two sub-dimensions in each ring in order to be more inclusive of third alternatives that are not covered by the binaries planned/unplanned, positive/negative and tangible/intangible. This radical move from dyadic towards triadic thought will be developed through an engagement with related debates in the context of ANT.

\section{ANT and the 'trinity of actants'}

Actor-network theory (ANT) emerged in the 1980s through sociological studies of scientific practice by a group of scholars located in Paris, including Michel Callon, Bruno Latour, John Law and Arie Rip (Callon, Law, \& Rip, 1986). Aiming to understand how scientists work and how scientific knowledge is constituted, actor-network theorists began to critique several reductionist dichotomies of social theory that they encountered during their research, such as object/subject, nature/society, small scale/large scale and agency/structure (Latour, 1993). ANT thus became a project of first dissolving such restrictive a priori binaries of social theory and then reconstructing connections between apparently ontologically disparate poles, either by following or retracing particular network-building processes between their 
constitutive entities (Latour, 2005). Accordingly, dichotomies such as nature/society were no longer regarded as the starting point of empirical analyses that would examine which category impacted on the other but as the outcome of scientific (and later also other) work that would need to be understood (Latour, 1992).

Over the past three decades, ANT-based research has produced new insights in a range of academic disciplines beyond science and technology studies by helping to understand the ‘emergence and experience of “things”' (Fenwick, 2011, p. 114). Prominently discussed in sociology (e.g., Latour, 2005), geography (e.g., Jöns, 2006), urban studies (e.g., Farías \& Bender, 2010), education (e.g., Fenwick \& Edwards, 2010) and tourism studies (e.g., van der Duim, Ren, \& Jóhannesson, 2013), ANT is also beginning to be fully utilized for the benefit of sports-related leisure studies (Kerr, 2016). This section introduces key arguments of ANT before these are used to illustrate the limitations of dualistic thinking in comparison to the greater value of non-dualistic and especially triadic thought.

The first departure of ANT from conventional social theories emerged through a completely different understanding of agency because this notion is not limited to humans. Within ANT, an actor is considered to be any entity that affects a change on the final process outcome (Latour, 2005). Agency is thus not regarded as a property of humans but of an association of heterogeneous entities, the so-called 'actants' (Latour, 1999b, p. 183). By introducing the concept of actants as an umbrella term for human beings and various nonhuman entities, such as buildings, books, computers and non-human organisms, ANT extended the notion of agency beyond humans to a collective of humans and nonhumans (Latour, 1992; 1999b). All actants are involved in different network-building processes, in which they share the responsibility for action and thus collectively produce new actants (Latour, 1999b). The actants' individual contribution to processes of network formation, i.e. 
their actual power within the network of which they form a part, is understood as a relational effect that depends on the particular network configuration (Whatmore, 1999).

The second departure of ANT from conventional social theories acknowledged that nonhuman entities (or 'nonhumans') can incorporate both material and social characteristics, thus blurring previously 'pure’ ontological domains of subjects/objects or society/nature. Consequently, ANT introduced the concept of sociomaterial hybridity resulting from both the socialisation of matter and the materialisation of ideas (Latour, 1999b). ANT thus implies that all actants, such as physical infrastructure and objects, technologies, people and organisms, are outcomes as well as mediators of network formations. Since all actants are involved in exchanges of properties within network-building processes, their nature is constantly being transformed (Figure 2). According to ANT's so-called 'generalized principle of symmetry' (Latour, 1993, p. 95), humans and nonhumans should thus be treated symmetrically when analysing how networks are formed, how social relations are stabilised, how new actants develop and how their power-relations change (Latour 1999b, p. 182).

\section{[Please insert Figure 2 about here]}

ANT greatest achievement has most likely been to draw attention to the ways in which material objects, resources and infrastructures have shaped human interactions and contributed to both the stabilisation of social structures and the channelling of human practices (Urry, 2007). Against both realist and social constructivist understandings of knowledge production, Latour (1999b, p. 275) convincingly argued that outcomes of practices are not either 'real' or 'constructed' but that they may appear to be real, robust and autonomous precisely because they have been very well constructed (Figure 2). This understanding is very close to Giddens' (1979) concept of the 'duality of structure' as 'both 
medium and outcome of the reproduction of practices' (p. 5), but, by attributing agency to material structures, ANT acknowledges the existence of construction processes within the non-human material world that proceed independently of human (social) practices.

Despite ANT’s important contributions to social theoretical debates, critics have argued that the new symmetry of humans and nonhumans does also not consistently account for all entities shaping network-building processes. In science studies, Shapin (1988, p. 547) and Bloor (1999, p. 87) pointed out that ANT lacks references to people’s 'independent interests' and 'beliefs about, or accounts of, nature', while geographers criticised that 'actornetwork theory cannot speak of certain things’ (Thrift, 1999, p. 313) such as emotion, memory, language, metaphors and other intangible phenomena (see also Murdoch, 1997, p. 752). In comparison to Giddens' (1979) duality of structure, it is also evident that material mediums and outcomes of practices have been overemphasised in ANT's 'material semiotics' (Law, 2009, p. 142) at the expense of its immaterial counterpoint, or what Giddens (1984) designated as 'memory traces orienting the conduct of knowledgeable human agents' (p. 17). This means that there is clear scope for developing ANT-based thinking further as a repertoire to 'walk new roads' (Mol, 2010, p. 261),

In the context of these criticisms, Jöns (2001; 2003a; 2003b; 2006) developed a constructive critique of ANT's new generalized symmetry between humans and nonhumans, arguing that ANT's focus on material mediators and outcomes of practices has resulted in the neglect of previous social constructivist research foci, such as the role of human interests, beliefs, and prior knowledge in the production of scientific knowledge. Based on an in-depth analysis of first, a heated debate between David Bloor (1999) and Bruno Latour (1999c) about the strengths and weaknesses of social constructivism and ANT; second, related debates in science and technology studies and in geography; and third, poignant insights by philosophers Donna Haraway, Henri Lefebvre and Michel Serres, Jöns (2003a; 2006) proposed the 
alternative notion of a 'trinity of actants' that outlines how both material and immaterial entities, as the respective conceptual foci of ANT and social constructivism, are produced, mediated and transformed through the practices of humans and other 'dynamic hybrids', who are able to connect the realms of matter and meaning because they resemble a dynamic combination of their constitutive material and immaterial entities (Figure 3).

\section{[Please insert Figure 3 about here]}

In this paper, we argue that these conceptual debates can be productively used for mega event studies because they enable a theoretically-grounded extension of Preuss' (2007) prominent binaries tangible/intangible, positive/negative and planned/unplanned to more inclusive triads. In the case of the tangible/intangible dyad, this means that the related previous foci of mega event studies on tangible built environment and intangible memories, symbols and heritage can be significantly broadened through a new focus on human agency that considers, for example, the practices and lived experiences of the general public visiting post-event spaces, as part of both event legacies and leveraging strategies. Accordingly, it is important to understand the argumentative nuances that can shift conceptual debates from the restrictive binaries tangible/intangible, human/nonhuman and agency/structure to more inclusive triads of social theory by examining the conceptual moves that have led from ANT's binary of humans and nonhumans to a complex trinity of actants.

The first of three conceptual moves that created the trinity of actants complements ANT's overfocus on materialities by acknowledging the important role of intangible and invisible actants, or immaterialities, as mediators and outomes of practices. Immaterialities represent the realms of intangible knowledge and skills, information and ideas, memories and meaning, imaginations and interests, emotions and instincts. Materialities, in turn, refer to 
tangible actants such as buildings, sports equipment and other sociomaterial things (Jöns, 2006). As Preuss’ (2007) legacy cube illustrates, differentiating these two types of tangible/intangible actants is important, especially because the invisible ones might easily be overlooked. In addition, however, we argue that considering these temporarily stabilised ‘structures’ without agency leaves out a significant and hitherto under-researched aspect of mega event legacy.

The second conceptual move therefore aims to explain how these different types of material and immaterial actants are (re)produced, transformed and tied together through practices. Building on Latour’s (1999b) considerations, Jöns (2006) argued that the ontological difference of materialities and immaterialities can only be bridged by the practices and performances of people and other dynamic hybrids 'able to negotiate between matter and meaning because their abilities are based on a [dynamic] combination of both realms' (p. 571). Accordingly, Jöns (2001; 2003a; 2006) stressed the ‘dynamic hybridity’ of human agents resulting from both the corporeality of their body (and its constitutive material actants) — thus enabling them to transform material environments — and their cognitive abilities_-allowing them to create, recognise and communicate meaning. The notion of dynamic hybridity thus provides a conclusive explanation of how material and immaterial mediators and outcomes of practices are constantly being produced and reproduced. Drawing upon Lefebvre’s (1991) observation that 'the living body, being at once "subject” and “object” cannot tolerate such a conceptual division’ (p. 407), this understanding therefore introduces a much needed, mediating third category into dualistic social theory (Latour, 1999b, p. 69; Zierhofer, 1999, p. 3).

The third conceptual move that led to the 'trinity of actants' aimed to dissect ANT's category of the nonhuman by pointing to a crucial difference between ANT’s classic sociomaterial hybridity of things, such as sculptures and buildings, resulting from their hybrid 
construction history, and the dynamic hybridity of humans, animals, other organisms, robots and similar machines that all share, if alive or running, 'a continuous circulation [of blood, water, electricity] providing a dynamic connection between their material, immaterial and dynamically hybrid components and thus a greater scope of negotiation than non-dynamic actants can use for network-building' (Jöns, 2006, p. 573). The resulting complex trinity of actants thus identifies humans and other dynamic hybrids as dynamic mediators that are able to perform practices and thus to negotiate between temporarily differentiable material and immaterial actants and their respective actor-networks, larger associations and functioning black boxes (Figure 3; see also Jöns, 2001, p. 118).

This triadic concept of actants therefore identifies practices as a central mechanism for the materialisation of ideas and the socialisation of matter. It accounts for symbolic entities that are excluded from the binary of humans and nonhumans (Sayes, 2014, p. 136) and also presents a response to Müller's (2015b) concern that '[i]n the turn to materialities, the preoccupation of the cultural turn with symbolic orders may have somewhat faded from view’ (p. 36) because it precisely integrates both perspectives and links them through the practices of humans and other dynamic hybrids such as robots (Del Casino, 2015). Against the background that the trinity of actants has originally been developed in the context of regional transformation in Hungary—considering (im)material socialist legacies and new capitalist actants as well as human actors escaping such a classification due to their dynamically hybrid nature (Jöns, 2001, pp. 117-18) — and most recently been useful for the conceptualisation and better understanding of dance performer training (Camilleri, 2015), the next section will elaborate in more detail why we think that it can also enrich the study of mega events. 


\section{Conceptualising the 'legacy rings'}

Based on the previous considerations, we argue that studying the outcomes of mega events can benefit significantly from triadic thought because this means taking seriously the constitutive significance of (1) material things, infrastructure and the physical environment (the tangible); (2) immaterial thoughts, meanings and knowledges (the intangible); and (3) humans and other dynamic hybrids capable of conducting practices that negotiate between these ontologically different realms. Tangible and intangible aspects represent wellestablished lines of inquiry in mega event studies, such as the built environment and Olympic visions, whereas the practices of humans (and other dynamic hybrids) in (post-)event spaces, and how these vary between different populations, have conceptually and empirically largely been neglected due to an over focus on economic revenue and trickle-down effects (O'Brien \& Chalip, 2008; Weed et al., 2012; Preuss 2015; for an exception, see Cashman, 2011).

We therefore argue that applying this more inclusive triadic thinking to Preuss' (2007) legacy cube enables us to overcome some of the restrictions of reductionist binaries by outlining three dimensions per category respectively. By combining the two key works of Preuss’ (2007) legacy cube and Jöns’ (2006) trinity of actants, we specifically propose the novel framework of the legacy rings as a multidimensional concept for understanding the effects, impacts and legacies of sport mega events. The five main research perspectives of the legacy rings are extending Preuss’ (2007) legacy cube by visualising agency, intention, evaluation, time and space respectively (Figure 4). Within each of these five dimensions, we unfold triads of sub-dimensions that are more complex than dyads and thus more inclusive but still manageable to comprehend. This results in the visualisation of a systematic research agenda in two ways. First, this agenda helps to position the foci of existing case studies in relation to each other. Second, based on the understanding that most likely no empirical case study would be able to account for all dimensions at the same time, the concept of the legacy 
rings allows for the development of new, context-specific research perspectives that emphasise some dimensions and sub-dimensions more than others.

[Please insert Figure 4 about here]

\section{Agency}

The most prominent and novel addition to the conceptual debate is the ring on agency because it differentiates the constitutive entities of network-building in the planning, staging and aftermath of mega events. Drawing on Jöns’ (2006) synthesis of social constructivist and actor-network based research foci, the main constituents of the wider actor-networks related to mega events can be addressed as humans and other dynamic hybrids negotiating between material and immaterial entities. Materialities relate to the tangible structures explored by Preuss (2007) and are most evident in the built environment and the physical infrastructure of mega events, whereas immaterialities comprise of their intangible aspects. Revolving around visions and imaginations, knowledge and ideas, expectations and experiences, discourses and memories, emotions and feelings, such immaterialities include the 2012 Olympics' aspiration to 'inspire a generation' as well as the knowledge transfer connecting former and future host cities (Halbwirth \& Toohey, 2015).

The third dimension that we add to these two well-established research perspectives comprises the practices of people using mega event spaces. This is because practices are not mentioned in Preuss’ (2015) five ‘event structures’ of infrastructure, knowledge, policy, networks and emotions 'that can be created to a greater or lesser extent by a mega event' (p. 651). Practices such as sports participation (Weed, 2014), sightseeing, consumption and tourism (Weed, 2015) and the social interaction at the community level, as stressed by leveraging studies (e.g., Chalip, 2006; O’Brien \& Chalip, 2008), are bound to the dynamically 
hybrid nature of people, who constantly shape the impact and legacies of mega events by interacting with the built environment, spreading memorabilia near and far and conveying their experiences and evaluations to other people. Much of this interaction, as in the case of the interactive iPads entertaining visitors on top of the ArcelorMittal Orbit in The Park, is mediated by technologies that share core features of humans’ dynamic hybridity, thus supporting the visitors' agency as informants, interpreters and translators and extending their lived experience in time and space (Jöns, 2006).

From this triadic actor-network perspective, urban regeneration projects associated with Olympic Games are largely transforming material urban space, but they need to be addressed as heterogeneous actor-networks involving all three types of material, dynamically hybrid and immaterial actants as well as the complex structures resulting from their interactions. The latter include (im)material structures, such as swimming pools and Olympic memories, but also typical patterns of how (post-)mega events sites are used on an everyday basis, thereby (re)producing predominant visitor profiles, practices and perceptions. These warrant closer academic attention because they may implicate complex politics of socioeconomic and cultural in- and exclusion. In consequence, all three sub-dimensions of the agency dimension could serve as equally interesting starting points for context-specific empirical analyses - whether it is the plans underlying regeneration projects (the immaterial dimension), the actual transformation of the built environment (the material dimension) or the resistance, compliance and creative contributions of people affected by the process (the practices).

\section{Intention}

The bidding process for mega events such as the Olympics includes sophisticated development plans for post-event futures that are drafted by hosting bodies with the aim of 
stressing the creation of beneficial legacies for the people and places involved. In regard to London 2012, these legacy goals were bundled into five broad planning categories: elite sport, regeneration, inspiration, sustainability and advertising of the UK (LOCOG, 2004). Whereas the planned impacts of mega events are often evaluated at different stages during and after the actual event, the triadic approach applied in this paper suggests that for achieving a comprehensive understanding of mega event legacy, it is equally important to consider unplanned impacts and those impacts that were planned but not implemented (O’Brien \& Chalip, 2008, p. 322). Given that host bodies develop plans up to a decade prior to an event and often overindulge these in order to be seen as the most attractive city in the bidding competition, a more systematic comparison of planned and implemented with planned and not implemented impacts of mega events at the levels of both academic studies and policy making might also help to avoid the danger of causing disappointment in the long-term. This is because the current demand placed on cities to 'win' their bid through ambitious legacy plans tends to generate ever more unrealistic narratives with a large number of promises later being discarded, changed or forgotten.

\section{Evaluation}

Changes associated with mega events are often considered positive or negative depending on the perspective of the particular researcher, organisation or interest group. Whereas many authors stress that evaluations of mega event legacies remain highly ambivalent because positive outcomes for one group of people can mean negative results for others (Gaffney, 2015), most official evaluation studies have examined positive aspects of legacy (Preuss, 2007). In turn, recent academic studies have overemphasised negative outcomes of mega events (e.g., Lenskyj, 2002; Gaffney, 2010). In the light of triadic thought, we suggest that the binary of positive and negative impacts could usefully be complemented by a third category 
that subsumes neutral, or indifferent, aspects resulting from mega events. These neutral legacies link positives and negatives along a spectrum of relational evaluations and acknowledge two things: first, not all changes will affect people and places in either a positive or a negative manner; and second, positives and negatives might balance each other out for individual stakeholders. For instance, local community groups may be able to take advantage of facilities in the long-term but suffer from construction-related disruption in the short-term (Roult et al., 2014). This conceptual move thus allows for contextualised debates about a greater variety of perceptions rather than stating categorically that a change is either positive or negative.

\section{Time}

Brimicombe (2015) stresses that one should not try to measure legacy too soon because the emergence of main transformations would take fifteen to twenty years. Accordingly, we agree with the point made by leveraging studies to speak more generally about strategies and outcomes of mega-events (O’Brien \& Chalip, 2008) and suggest that the term 'legacy' should be applied more concisely to "long-term, sustainable outcomes” (p. 318) of mega events, alongside medium-term 'impacts' and short-term 'effects'. Even if such more precise timeframes need to be critically reflected upon in different contexts, we propose that a triadic approach to Olympic legacy could appropriately differentiate three overlapping phases: first, effects caused in the period prior to the Olympic Games up until the end of the subsequent Paralympic Games; second, impacts that are most clearly visible in the period from the beginning of the Olympic Games until the first post-Games decade; and third, legacy as it emerges one or more decades after Olympic Games. Accordingly, research on the outcomes of Barcelona 1992 — conducted in 2017—could be understood as legacy research, while scholarship on Beijing 2008—conducted at the same time—should still be considered as 
impact studies. The three differently labelled timespans for measuring outcomes of mega events constitute a continuum in which boundaries become blurred if one tries to separate them neatly, but they nevertheless provide more conceptual clarity about different research foci and thus help to compare evaluation studies with similar timeframes. Moreover, such a differentiated triadic understanding of effect - impact - legacy helps to reduce overambitious expectations about the creation of ‘instant legacy’ among various stakeholders.

\section{Space}

Most studies on the legacy of mega events have focussed on the immediate spatial environment of the host city or region (e.g., Kissoudi, 2009; Poynter \& MacRury, 2009). Only recently have researchers begun to scrutinise the wider geographical reach of mega events, for example, by exploring the physical activity levels of families in the East Midlands, UK, during the London 2012 Olympic Games (Mackintosh et al., 2014). Systematic triadic thought not only means to differentiate micro/meso/macro scales when examining the outcomes of mega events but also implies to separate the intensity of effects/impacts/legacies from specific spatial scales by allowing for the empirical manifestation of all possible combinations. In other words, the emotional impact of London 2012 was at times more profound on the national level than on residents in local neighbourhoods (Kohe \& BowenJones, 2015). Such a relational understanding of space links well with a conceptualisation of mega events as central nodes of heterogeneous actor-networks displaying complex and constantly changing spatial configurations and thus translating into equally spatially diverse effects/impacts/legacies. Given the global reach of sportscapes (Bale, 1989) and initiatives such as London 2012’s ‘international inspiration’ (UK Government, 2013), capturing the full picture of mega event leveraging and legacies requires the consideration of local, regional, national and international scales (Preuss, 2014). We therefore suggest that these scales can 
again be captured by a flexible continuum of three sub-dimensions that may vary by case study context, namely the micro/meso/macro spaces of mega events.

\section{A case study of the Queen Elizabeth Olympic Park}

London’s bid for the Olympic Games in 2012 was considerably shaped by an IOC Charter amendment in 2002 that explicitly emphasized the 'positive legacy' of mega-events (Weed, 2015). Accordingly, studies about London’s ‘legacy’ have proliferated since 2012 (e.g., Viehoff \& Poynter, 2015). In this final section of the paper, we aim to show how the proposed conceptual framework of the legacy rings sketches a research agenda that helps to provide a comprehensive overview on relevant triadic dimensions, thereby elucidating aspects of megaevent leveraging and legacy that have received less attention than sports participation, the built environment and economic revenue.

We provide two empirical examples taken from a larger case study on the profiles, practices and perceptions of visitors to the Queen Elizabeth Olympic Park. We specifically draw upon a longitudinal visitor survey conducted in The Park on 15 days for eight hours respectively between February 2014 and December 2015 (n = 652 responses; see Dawson, 2015). Disentangling different forms of agency, the first empirical example focuses on the perspective of human actors by analysing the profiles and practices of visitors from local neighbourhoods and the UK. Conceptually, this combines a focus on human agency (the added dimension of dynamic hybrids) with a comparison of micro and meso scales (Figure 4). The second empirical example discusses the instance of the planned but not implemented Olympic Museum. This examination of an attempt to enrich the material and immaterial legacies of London 2012 as part of a wider entertainment spectacle combines an interest in (im)material agency with the added dimension of planned but not implemented intentions (Figure 4). 


\section{Park visitor profiles and practices}

The Queen Elizabeth Olympic Park is located within the four London Boroughs of Hackney, Newham, Tower Hamlets and Waltham Forest (Park Boroughs). During the London 2012 Olympic and Paralympic Games, the territory of The Park hosted a third of all sporting venues. Historically, this was a site of the 'stink' industries linked to London's extensive dockyards (Butler \& Hamnett, 2011). Rapid deindustrialization since the 1970s has changed the economy of the adjacent Dockland area that serves now as a hub for advanced producer services. As part of a progressive tertiarisation of capitalist urban economies, the former mixed industry, railway infrastructure and social housing area—centred on Newham’s Stratford ward east of Fish Island and Hackney Wick—-was identified in the early 2000s as an ideal site for urban regeneration through the London Olympics. It has since been transformed into a post-industrial space with extensive leisure and shopping facilities, schools and universities, sculptures and artwork, and a creative industry hub (Viehoff, 2015).

The Queen Elizabeth Olympic Park was opened to the general public in different stages throughout 2014 and 2015. Most Park visitors live in the four adjacent Park Boroughs (44\%) and use The Park for sports participation (all visitors: 37\%; Park Borough visitors: 52\%). Interestingly, the ethnic background of local Park visitors varies substantially from the ethnic composition of the Park Boroughs. While the East End of London has historically been an immigrant reception area of ethnically diverse blue collar workers, a new phase of gentrification since the 1980s has increased the share of residents from the white middle classes (Davidson \& Lees, 2005). This is reflected in a striking overrepresentation of those visitors to The Park who live in the Park Boroughs and identify themselves as 'White' (Table 1). Yet it is important to note that this pattern of inclusion/exclusion does not apply at the meso scale because visitors from the UK are more ethnically diverse than the country's population (Table 1). 


\section{[Please insert Table 1 about here]}

Consequently, it appears that urban regeneration has created a post-industrial space of socio-cultural exclusion catering for the new 'East Ender' but not attracting local Asian and Black minorities. Focussing on human practices at the micro level of The Park thus reveals a clearly unintended negative impact of socio-cultural exclusion that is in stark contrast to the legacy plans envisioning a wider engagement and inspiration of local communities through The Park development (DCMS, 2008). As the Park Boroughs’ Asian and Black minorities tend to be from less affluent backgrounds than those of the UK’s overall population (National Statistics, 2015), The Park has created local socio-cultural exclusion, or what Silk (2014) aptly characterizes as ‘a divisive social geography’ (p. 58) resulting from the 'political and economic rationalities of neoliberalism' (p. 54). Importantly, this form of exclusion only emerges to be a primarily socio-economic discrimination when comparing the representation of ethnic minorities at different geographical scales such as the Park Boroughs and the UK.

From a policy perspective, this finding extends O’Brien’s (2006) previous observation that business leveraging strategies—aiming to stimulate post-Games business relationships and activity in the host community — benefitted larger businesses more than small- and medium-sized businesses from the economic sphere to the dimension of visitors of postGames spaces because here, too, the financially stronger agents have been clearly advantaged. In conceptual terms, this point underlines the significant added value of the triadic legacy rings as a conceptual framework because it stresses the need to examine park visitors' profiles and practices — thus considering human agency as part of effects/impacts/legacies—at different geographical scales to avoid misinterpretations and inadequate generalisations. 


\section{Olympic memories and local heritage}

The imprints that events leave on a space and especially a host city's heritage include not only material structures but also immaterial meanings and lived everyday experiences (Bairner, 2015). Immaterial history and heritage can be experienced through discourses, memory and storytelling. Perhaps most compellingly, the tragedy associated with the Munich 1972 Olympics highlights the immaterial heritage of an event because the assassination of eleven Israeli athletes during the Munich Games remains closely anchored in public memory (Mandell, 1991). Apart from physical infrastructures (e.g. sports infrastructure and housing), a number of mega event sportscapes also host specific museum venues for commemoration, knowledge transfer and public learning. On a global scale, seventeen Olympic cities had constructed such sites by 2015, thus offering a physically-embedded cultural memory of the specific Games, IOC heritage and sport more generally.

Six months prior to the London 2012 Games’ opening ceremony, it was announced that the Olympic Park would also host a space dedicated to providing a permanent commemorative record of the three Olympics hosted by London in 1908, 1948 and 2012 (Gibson, 2012). Only a year later, these plans had to be cancelled because the climate of austerity politics had made it impossible to raise the ten million pounds required for this development. Representing a key example for planned but not implemented legacy, the London Olympic Museum continues to exist as an idea and a concept that could improve the visitor experience in the future. Having failed to be materialised at present, its envisioned site is currently being converted into another commercial development, the Olympicopolis scheme, a new educational and cultural district in The Park, which underlines the emphasis on private rather than public investment.

In this rivalry between profit, non-profit and public institutions over their presence in East London's transformed Olympic Park, the commemoration of local industrial and cultural 
heritage has focused on alternative strategies to the traditional museum setting. These include permanent sport venues like the Aquatics Centre; temporary sites such as frequently changing small-scale art instalments; and landscaped spaces such as Mandeville Place, an orchard in celebration of the success of Team GB's Paralympic medal winners, and the interactive 'green spots' challenging visitors to jump like Greg Rutherford. ${ }^{\mathrm{i}}$ These initiatives show that despite the failure to construct the London Olympic Museum, the commemoration of both London 2012 and local industrial heritage remains a key strategy for attracting additional visitors and economic revenue to London’s post-industrial East End. Furthermore, all planned but not (yet) implemented legacy initiatives help to identify future potentials for enhancing the visitor experience in London and other mega event spaces. Visualising five legacy rings with their triadic sub-categories thus helps to avoid overlooking those aspects that have previously not been displayed in Preuss' (2007) legacy cube-whether it is human agency in the first or planned but not implemented intention in the second example—-and thus to develop new research perspectives on mega event effects/impacts/legacies.

\section{Conclusion}

This paper contributes to mega event legacy and leveraging research by proposing the conceptual framework of the 'legacy rings' as both an ordering mechanism for existing case studies and an agenda for future research. The legacy rings take inspiration from two bodies of academic debate by joining recent insights into mega event legacy theory (MELT) and writings on actor-network theory (ANT). More specifically, the legacy rings combine the five research dimensions outlined by Preuss’ (2007) notion of the legacy cube with systematic triadic thinking inspired by Jöns’ (2006) trinity of actants, a concept that identifies material, dynamic hybrid and immaterial entities as the three main constituents of network-building processes examined with the tools of ANT. 
Drawing on the case study of a longitudinal visitor survey in East London's Queen Elizabeth Olympic Park, we have demonstrated the usefulness of triadic thought in the context of the multidimensional legacy rings by considering short-term effects and mediumterm impacts as building blocks of long-term mega event legacy (time dimension). We have also stressed the importance of considering practices of humans, at times in conjunction with other dynamic hybrids, and related lived experiences in addition to hitherto emphasised tangible/material and intangible/immaterial mega event outcomes (agency dimension). By examining the ethnicity of Park visitors, we have shown that to avoid misinterpretations and inadequate generalisations, visitor practices need to be traced beyond the local event site to include wider regional, national and global scales. Effects/impacts/legacies should thus either be compared at similar micro/meso/macro scales or studied across different geographical scales (space dimension). The example of the London Olympic Museum has illustrated how planned and unplanned effects/impacts/legacies need to be complemented by systematic studies of their planned but not implemented equivalents in order to identify strategies for enhancing the visitor experience and encourage more specific, detailed and realistic legacy plans in other mega event bids (intention dimension). Future research could usefully examine the nuances and ambiguities of visitors’ positive, negative and neutral perceptions of The Park and its Olympic legacy, and how these immaterial actants are subsequently circulated across the world (evaluation dimension).

In summary, we argue that the five main research dimensions discussed in MELT can be substantially enriched through systematic triadic thought. This conceptual move widens the research lens beyond restrictive binaries of social theory that ANT has criticised in such a masterly manner (e.g., Latour, 1992) but, as Jöns (2003; 2006) has argued, without going beyond the newly created binary of humans and nonhumans. We suggest that the resulting triadic conceptual framework of the legacy rings helps to contextualise existing studies on the 
outcomes of mega events, to identify neglected areas for future research and to formulate comprehensive event leveraging strategies. Future research needs to analyse different intensities of effects/impacts/legacies, as visualised in Dickson, Benson, and Blackman’s (2011) legacy radar by a six point Likert scale, and compare effects/impacts/legacies across different axes of social difference such as people's gender, age, race, ethnicity and place of residence. From such a differentiated perspective, the two key findings from the longitudinal visitor survey in the Queen Elizabeth Olympic Park discussed in this paper are unplanned impacts. First, the exclusion of socioeconomically less affluent, local ethnic minorities and inclusion of more affluent ethnic minorities from other parts of the UK evidences that capitalist festivalisation caters only for those who can afford it - no matter what ethnic background. Second, it has emerged that the politics of commemoration are such an important aspect of post-mega event spaces that commemoration strategies are flourishing despite the fact that the key venue of the London Olympic Museum has not yet been implemented for financial reasons.

\section{References}

Allen. J., et al. (2011). Festival and special event management. Oxford, OXON: John Wiley \& Sons.

Bairner, A. (2015). The legacy of memory: the Stockholm and Helsinki Olympic stadia as living memorials. In R. Holt \& D. Ruta (Eds.), Routledge Handbook of Sport and Legacy (pp.120-130). London: Routledge.

Bale, J. (1989). Sports geography. London: E \& FN Spon.

Biagioli, M. (1999). The sciences studies reader. New York: Routledge. 
Black, D. (2014). Megas for strivers: the politics of second-order events. In J. Grix (Ed.), Leveraging legacies from sports mega events (pp. 13-23). Basingstoke: Palgrave MacMillan.

Black, D., \& Bezanson, S. (2004). The Olympic Games, human rights and democratisation: lessons from Seoul and implications for Beijing. Third World Quarterly, 25, 7, 12451261.

Bloor, D. (1999). Anti-Latour. Studies in history and philosophy of science, 30, 1, 81-112.

Brimicombe, A.J. (2015). How do we measure legacy? In V. Viehoff \& G. Poynter (Eds.), Mega-event cities: urban legacies of global sports events (pp. 33-46). Farnham: Ashgate.

Butler, T., \& Hamnett, C. (2011). Ethnicity, class and aspiration: understanding London's new East End. Bristol, UK: Policy Press Ltd.

Callon, M., Law, J., \& Rip, A. (1986). Mapping the dynamics of science and technology. London: MacMillan Press Ltd.

Camilleri, F. (2015). Of hybrids and the posthuman: performer training in the $21^{\text {st }}$ century. The Drama Review, 59, 3, 108-122.

Cashman, R. (2005). The bitter-sweet awakening: the legacy of the Sydney 2000 Olympic Games. Sydney: Walla Walla Press.

Cashman, R. (2011). Sydney Olympic Park 2000 to 2010: history and legacy. Sydney: Walla Walla Press.

Chalip, L. (2006) Towards social leverage of sports events. Journal of Sport and Tourism, 11, 2, 109-127.

Chalip, L. (2014). From legacy to leverage. In J. Grix (Ed.), Leveraging legacies from sports mega events (pp. 2-12). Basingstoke: Palgrave MacMillan. 
Davidson, M., \& Lees, L. (2005). New-build ‘gentrification’ and London’s riverside renaissance. Environment and Planning A, 37, 7, 1165-1190.

Dawson, J. (2015). Parklife: practices of Queen Elizabeth Olympic park visitors. Unpublished oral presentation, 1st Sport and Discrimination Conference, May 1, 2015, London, UK.

DCMS. (2008). Legacy action plan: 'before, during and after: making the most of the London 2012 Games’: Retrieved October 3, 2015 from http://webarchive.nationalarchives.gov.uk/20080610183507/http:/www.culture.gov.uk/r eference_library/publications/5161.aspx

DCMS. (2014). Inspired by 2012: the legacy from the Olympic and Paralympic Games. Retrieved October 15, 2015 from https://www.gov.uk/government/uploads/system/uploads/attachment_data/file/335774/1 40723_Inspired_by_2012_-_2nd_annual_legacy_report-accessible.pdf

Del Casino, V.J. (2015). Social geographies II: robots. Progress in human geography, DOI: 10.1177/0309132515618807.

Dickson, T.J., Benson, A.M., \& Blackman, D.A. (2011). Developing a framework for evaluating Olympic and Paralympic legacies. Journal of Sport \& Tourism, 16, 285-302.

Farías, I., \& Bender, T. (2010). Urban assemblages: how actor-network theory changes urban studies. London: Routledge.

Fenwick, T. (2011). Reading educational reform with actor network theory: fluid spaces, otherings and ambivalences. Educational Philosophy and Theory, 43, S1, 114-134.

Fenwick. T., \& Edwards, R. 2010. Actor-network theory in education. London: Routledge.

Gaffney, C. (2010). Mega-events and socio-spatial dynamics in Rio de Janeiro 1919-2016. Journal of Latin American Geography, 9, 1, 7-29.

Gaffney, C. (2015). Gentrification in pre-Olympic Rio de Janeiro. Urban Geography, DOI: 10.1080/02723638.2015.1096115 
Gibson, O. (2012). London 2012: Olympics museum plans unveiled, The Guardian 27 February. Retrieved November 28, 2015, from http://www.theguardian.com/ sport/2012 /feb/27/london-2102-olympics-museum-plans

Giddens, A. (1984). The constitution of society: outline of the theory of structuration. Oakland,CN: University of California Press.

Giulianotti, R., G. Armstrong, G. Hales \& Hobbs, G. (2015). Sport mega-events and public opposition: a sociological study of the London 2012 Olympics. Journal of Sport and Social Issues, 39, 2, 99-119.

Gotham, K.F. (2005). Theorizing urban spectacles: festivals, tourism and the transformation of urban space. City, 9, 2, 225-246.

Grix, J. (Ed.). (2014). Leveraging legacies from sports mega-events: concepts and cases. New York: Palgrave Macmillan.

Gruneau, R., \& Horne, J. (Eds.). (2016). Mega-events and globalization: capital and spectacle in a changing world order. New York: Routledge.

Halbwirth, S., \& Toohey, K. (2015). Transferring knowledge know-how and capability: managing and sharing knowledge for future events. In R. Holt \& D. Ruta (Eds.), Routledge Handbook of Sport and Legacy (pp. 245-258). London: Routledge.

Hiller, H.H. (1998). Assessing the impact of mega-events: a linkage model. Current Issues in Tourism, 1, 1, 47-57.

Holt, R., \& Ruta, D. (2015). Routledge handbook of sport and legacy: meeting the challenges of major sport events. London: Routledge.

Hylton, K., \& Morpeth, N.D. (2012). London 2012: 'race’ matters and the East End. International Journal of Sport Policy and Politics, 4, 3, 379-396. 
IOC. (2002). Provisional remarks, conclusions and recommendations, International Symposium on Legacy of the Olympic Games, 1984-2000, Lausanne, 14-16 November 2002. IOC: Lausanne.

Jöns, H. (2001). Foreign banks are branching out: changing geographies of Hungarian banking, 1987-1999. In P. Meusburger \& H. Jöns (Eds.), Transformations in Hungary: essays in economy and society (pp. 65-124). Heidelberg: Physica, A Springer Company.

Jöns, H. (2003a). Grenzüberschreitende Mobilität und Kooperation in den Wissenschaften: Deutschlandaufenthalte US-amerikanischer Humboldt-Forschungspreisträger aus seiner erweiterten Akteursnetzwerkperspektive. [Boundary-crossing academic mobility and collaboration: Research leaves of US Humboldt Research Award Winners from an extended actor-network perspective]. (= Heidelberger Geographische Arbeiten 116). Heidelberg: Selbstverlag des Geographischen Instituts der Universität Heidelberg.

Jöns, H. (2003b). Von Menschen und Dingen: konstruktiv-kritische Anmerkungen zum (a)symmetrischen Akteurskonzept der Akteursnetzwerktheorie. [Of humans and things: constructive-critical remarks on the (a)symmetric concept of actors in actor-network theory]. In J. Hasse \& I. Helbrecht (Eds.), Menschenbilder in der Humangeographie [Concepts of humans in human geography] (pp. 109-142). Oldenburg: BIS.

Jöns, H. (2006). Dynamic hybrids and the geographies of technoscience: discussing conceptual resources beyond the human/non-human binary. Social and Cultural Geography, 7, 4, 559-580.

Jöns, H. (2007). Transnational mobility and the spaces of knowledge production: a comparison of global patterns, motivations and collaborations in different academic fields. Social Geography, 2, 2, 97-114.

Kassens-Noor, E. (2012). Planning Olympic legacies: transport dreams and urban realities. London: Routledge. 
Kerr, R. (2014). From Foucault to Latour: gymnastics training as a socio-technical network. Sociology of Sport Journal, 31, 85-101.

Kerr, R. (2016). Sport and technology: an actor-network theory perspective. London: Bloomsbury

Kissoudi, P. (2009). The Athens Olympics: optimistic legacies post-Olympic assets and struggle for their realization. The International Journal of the History of Sport, 25, 14, 1972-1990.

Kohe, G.Z., \& Bowen-Jones, W. (2015) Rhetoric and realities of London 2012 Olympic education and participation 'legacies': voices from the core and periphery. Sport, Education and Society, DOI: 10.1080/13573322.2014.997693

Kuhn, T.S. (1962). The structure of scientific revolutions. Chicago, IL: University of Chicago Press.

Latour, B. (1987). Scientists in action: how to follow scientists and engineers through society. Cambridge, MA: Harvard University Press.

Latour, B. (1992). “One more turn after the social turn...”. In E. McMullin (Ed.) The social dimensions of science (pp. 272-292). Notre Dame, IN: University of Notre Dame Press.

Latour, B. (1993). We have never been modern. Cambridge, MA: Harvard University Press.

Latour, B. (1999a). On recalling actor-network theory. In J. Law \& J. Hassard (Eds.), Actor network theory and after (pp. 15-25). Oxford: Blackwell.

Latour, B. (1999b). Pandora's Hope: essays on the reality of science studies. Cambridge, MA: Harvard University Press.

Latour, B. (1999c). For David Bloor ... and beyond: a reply to David Bloor’s ‘Anti-Latour’. Studies in the History and Philosophy of Science, 30, 1, 113-129.

Latour, B. (2005). Reassembling the social: an introduction to actor-network theory. Oxford: Oxford University Press. 
Law, J. (2009). Actor network theory and material semiotics. In S.B. Turner (Ed.), The new Blackwell Companion to Social Theory (pp. 141-158). Oxford: Wiley-Blackwell. Law, J., \& Hassard, J. (Eds.). (1999). Actor Network Theory and after. Oxford: Blackwell Publishers.

Lefebvre, H. (1991). The production of space. Oxford: Wiley Blackwell.

Lenskyj, H.J. (2002). The best Olympics ever? Social impacts of Sydney 2000. New York: State University of New York Press

Leopkey, B., \& Parent, M.M. (2012). Olympic Games legacy: from general benefits to sustainable long term legacy. International Journal of the History of Sport, 29, 6, 924943.

LOCOG, (2004). London 2012: candidate file. London. Retrieved June 12, 2014 from http://webarchive.nationalarchives.gov.uk/20070305103412/http:/www.london2012.c om/news/publications/candidate-file.php

London Legacy Development Corporation, (2013). Art in the Park. London: London Legacy Development Corporation.

London Legacy Development Corporation, (2015). Local Plan: 2015 to 2031. Retrieved May 16, 2016 from < http://queenelizabetholympicpark.co.uk/ /media/lldc/local\%20plan/ adoption\%20july\%202015/lldc_localplan_2015_interactive100dpi\%20(4).pdf>

Mackintosh, C., Darko, N., Rutherford, Z., \& Wilkins, H. (2014). A qualitative study of the impact of the London 2012 Olympics on families in the East Midlands of England: lessons for sports development policy and practice. Sport, Education and Society, 20, 8, 1065-1087.

MacRury, I. (2015). Olympic legacy. In V. Viehoff \& G. Poynter (Eds.), Mega-event cities: urban legacies of global sports events (pp. 23-32). Farnham: Ashgate. 
Mandell, R.D. (1991). The Olympics of 1972: a Munich diary. Chapel Hill, NC: University of North Carolina Press.

Mascarenhas, G. (2014). Commodity city, shop-window cities, tourist city: the urban as spectacle in sports mega-events. Caderno Virtual de Tourismo, 14, 52-65.

Misener, L., Darcy, S., Legg, D., \& Gilbert, K. (2013). Beyond Olympic legacy: understanding Paralympic legacy through a thematic analysis. Journal of Sport Management, 27, 329-341.

Mol, A. (2010). Actor-network theory: sensitive terms and enduring tensions. Kölner Zeitschrift für Soziologie und Sozialpsychologie, 50, 1, 253-269.

Müller, M. (2014). A half-hearted romance? A diagnosis and agenda for the relationship between economic geography and actor-network theory (ANT). Progress in Human Geography, 1, 1-22.

Müller, M. (2015a). What makes an event a mega event? Definitions and sizes. Leisure Studies, 34, 6, 627-642.

Müller, M. (2015b). Assemblages and actor-networks: rethinking socio-material power, politics and space. Geography Compass, 9, 1, 27-41.

Murdoch, J. (1997). Inhuman/nonhuman/human: actor-network theory and the prospects for a nondualisitc and symmetrical perspective on nature and society. Environment and planning $D$ : society and space, $15,731-756$.

O’Brien, D. (2006). Event business leveraging: the Sydney 2000 Olympic Games. Annals of Tourism Leisure, 33, 1, 240-261.

O’Brien, D., \& Chalip, L. (2008). Sport events and strategic leveraging: pushing towards the triple bottom line. In A.G. Woodside \& D. Martin (Eds.), Tourism management: analysis, behaviour and strategy (pp. 318-338). Cambridge, MA: CAB International. 
Office for National Statistics. (2011). Quick Statistics: Ethnic Group. Retrieved 10 November 2014 from www.nomisweb.co.uk

Office for National Statistics. (2015). The English Indices of Deprivation 2015. Retrieved 1 June 2016 from https:/www.gov.uk/government/uploads/system/uploads/ attachment_data/file/465791/English_Indices_of_Deprivation_2015__Statistical_Release.pdf

Phillips, C., \& Barnes, M. (2015). Whose legacy is it anyway? A tale of conflicting agendas in the building of the Hamilton Pan Am Soccer Stadium. Annals of Leisure Research, 18, 4, 549-568.

Poynter, G., \& MacRury, I. (2009). Olympic cities: 2012 and the remaking of London. Farnham, UK: Ashgate.

Preuss, H. (2007). The conceptualization and measurement of mega sport event legacies. Journal of Sport \& Tourism, 12, 3-4, 207-228.

Preuss, H. (2014). 'Legacy’ revisited. In J. Grix (Ed.), Leveraging legacies from sports mega events (pp. 24-38). Basingstoke: Palgrave MacMillan.

Preuss, H. (2015). A framework for identifying the legacies of a mega sport event. Leisure Studies, 34, 6, 643-664.

Ritchie, J. R. B. (1984). Assessing the impact of hallmark events: conceptual and research issues. Journal of Travel Research, 23, 1, 2-11.

Roche, M. (2000). Mega-events and modernity: Olympics and expos in the growth of global culture. London: Routledge.

Roult, R., Adjizian, J.M., Lefebvre, S., \& Lapierre, L. (2014). The mobilizing effects and health benefits of proximity sport facilities: urban and environmental analysis of the Bleu, Blanc, Bouge project and Montreal North's outdoor rink. Sport in Society: Cultures, Commerce, Media and Politics, 17, 1, 68-88. 
Sayes, E.M. (2013). Actor-network theory and methodology: just what does it mean to say that nonhumans have agency? Social Studies of Science, 44, 11, 134-149.

Shapin, S. (1988). Following scientists around. Social Studies of Science, 18, 3, 533-550.

Silk, M. (2014). Neoliberalism and sport mega-events. In J. Grix (Ed.), Leveraging legacies from sports mega events (pp. 50-60). Basingstoke: Palgrave MacMillan.

Smith, A. (2012). Events and urban regeneration: the strategic use of events to revitalise cities. London: Routledge.

Smith, A. (2013). Leveraging sport mega-events: a new model or convenient justification. Journal of Policy Research in Tourism, Leisure and Events, 6, 1, 15-30.

Smith, A., \& Fox, T. (2007). From 'event-led' to 'event-themed' regeneration: the 2002 Commonwealth Games Legacy Programme. Urban Studies, 44, 5-6, 1125-1143.

Steinbrink, M., Haferburg, C, \& Ley, A. (2011). Festivalisation and urban renewal in the Global South: socio-spatial consequences of the 2010 FIFA World Cup. South African Geographical Journal, 93, 1, 15-28.

Thrift, N. (1999). Steps to an ecology of place. In D. Massey, J. Allen, \& P. Sarre (Eds.), Human geography today (pp. 295-322). Cambridge: Polity Press.

Tomlinson, A. (2014). Olympic legacies: Recurrent rhetoric and harsh realities. Contemporary Social Science: Journal of the Academy of Social Sciences, 9, 2, 137158.

Urry, J. (2007). Mobilities. Cambridge: Polity Press.

UK Government. (2013). Inspired by 2012: The legacy from the London 2012 Olympic and Paralympic Games. London: Cabinet Office.

Van der Duim, R., Ren, C., \& Jóhannesson, G. T. (2013). Ordering, materiality, and multiplicity: enacting actor-network theory in tourism. Tourism Studies, 13, 1, 3-20. 
VanWynsberghe, R. (2014). The Olympic Games Impact (OGI) study for the 2010 Winter Olympic Games: strategies for evaluating sports mega events’ contribution to sustainability. International Journal of Sport Policy and Politic, 7, 1, 1-18.

Viehoff, V. (2015). The legacy of the Olympic Park. In University East London (Ed.), Olympic Games impact study - London 2012 post games report (pp. 179-182). London: UEL

Viehoff, V., \& Poynter, G. (Eds.) (2015). Mega-event cities: urban legacies of global sports events. Farnham: Ashgate.

Wilson, W. (2015). Sports infrastructure, legacy and the paradox of the 1984 Olympic Games. The International Journal of the History of Sport, 32, 1, 144-156.

Weed, M., et al. (2012). Developing a physical activity legacy from the London 2012 Olympic and Paralympic Games: a policy-led systematic review. Perspectives in public health, 132, 2, 75-80.

Weed, M. (2014). Sport mega-events and mass participation in sport. In J. Grix (Ed.), Leveraging legacies from sports mega events (pp. 39-49). Basingstoke: Palgrave MacMillan.

Weed, M. (2015). Is tourism a legitimate legacy from the Olympic and Paralympic Games? An analysis of London 2012 legacy strategy using programme theory. Journal of Sport and Tourism, DOI:10.1080/14775085.20

Whatmore, S. (1999). Hybrid geographies. In D. Massey, J. Allen, \& P. Sarre (Eds.), Human geography today (pp. 22-39). Cambridge: Polity Press.

Zierhofer, W. (1999). Geographie der Hybriden. [A geography of the hybrids]. Erdkunde, 53, $1,1-13$. 


\section{Tables}

Table 1. The ethnicity of UK-based visitors to the Queen Elizabeth Olympic Park in comparison to census data (in percent). Source: Own visitor survey and Office for National Statistics, 2011.

\begin{tabular}{lllll}
\hline & Park Boroughs & Park Boroughs & UK Visitor Survey & UK Census \\
& Visitor Survey & Census (2011) & $(\mathrm{n}=594)$ & $(2011)$ \\
& $(\mathrm{n}=288)$ & & & 85 \\
White & 68 & 44 & 75 & 8 \\
Asian & 16 & 30 & 11 & 3 \\
Black & 6 & 17 & 5 & 2 \\
Mixed & 7 & 5 & 7 & 1 \\
Other & 4 & 4 & 2 & \\
\hline
\end{tabular}


Figures

Figure 1. The legacy cube. Source: Preuss, 2007, p. 211.

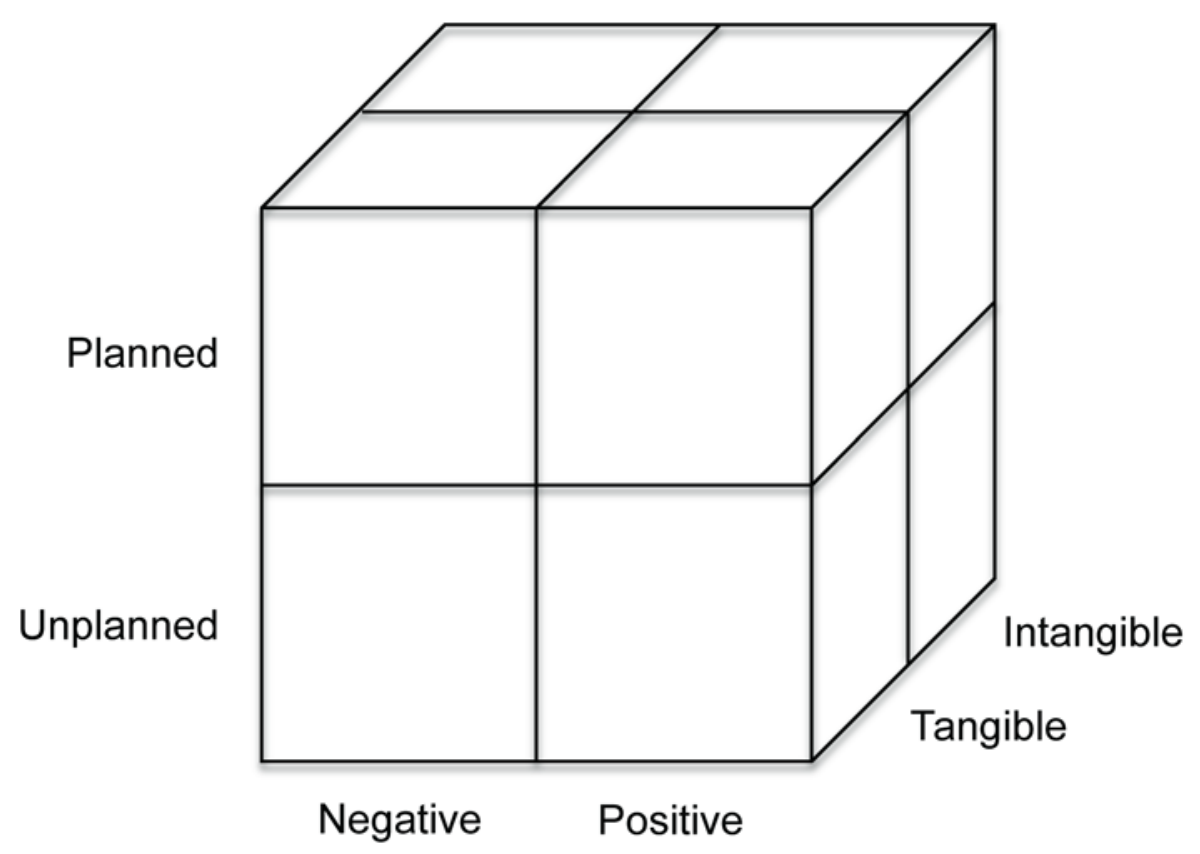


Figure 2. Network-building processes between humans and nonhumans according to ANT.

Source: Adapted from Jöns, 2003a, p. 95.

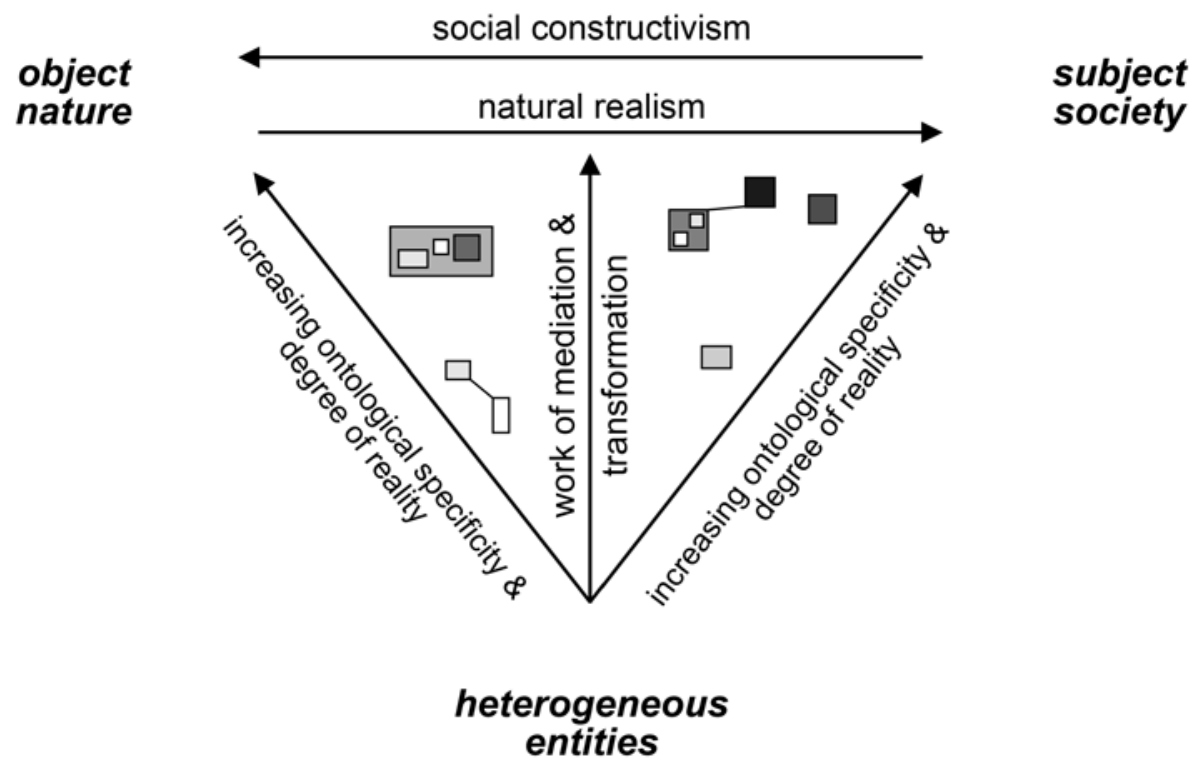

Figure 3. A complex trinity of actants. Source: Jöns 2006, p. 573.

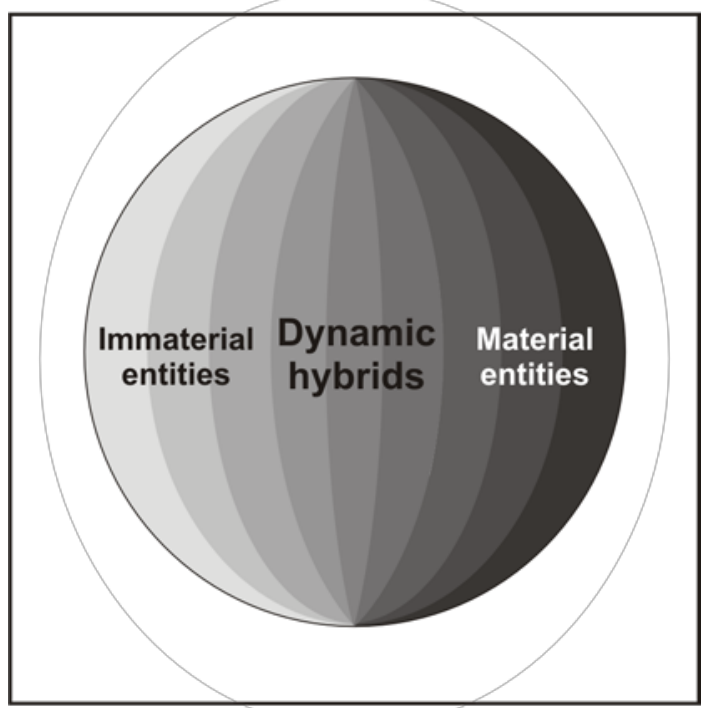


Figure 4. The legacy rings. Source: Own design.

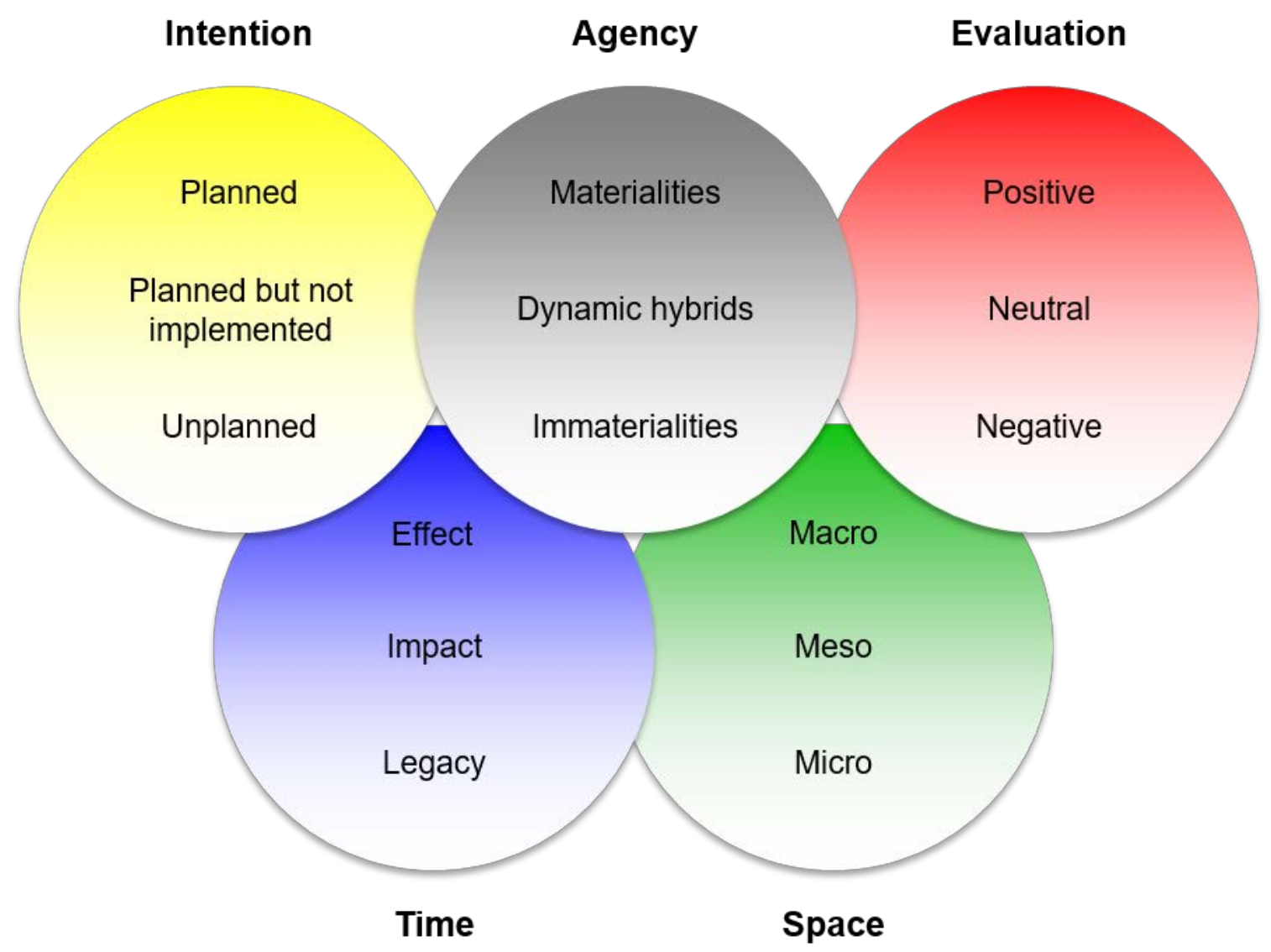

${ }^{\mathrm{i}}$ Greg Rutherford won Olympic gold in the long jump with a distance of 8.31m. 